\title{
Dualismo estructural andino y espacio novelesco arguediano
}

Dualisme structurel andin et espace romanesque arguedien

Andean structural dualism and arguedien novelistic space

Edmer Calero del Mar

(2) OpenEdition

Journals

Edición electrónica

URL: http://journals.openedition.org/bifea/6633

DOI: $10.4000 /$ bifea. 6633

ISSN: 2076-5827

Editor

Institut Français d'Études Andines

Edición impresa

Fecha de publicación: 1 agosto 2002

Paginación: 153-181

ISSN: 0303-7495

Referencia electrónica

Edmer Calero del Mar, «Dualismo estructural andino y espacio novelesco arguediano », Bulletin de I'Institut français d'études andines [En línea], 31 (2) | 2002, Publicado el 08 agosto 2002, consultado el 08 diciembre 2020. URL : http://journals.openedition.org/bifea/6633; DOI : https://doi.org/10.4000/ bifea.6633

\section{(2) $(\mathcal{\Theta \Theta}$}

Les contenus du Bulletin de l'Institut français d'études andines sont mis à disposition selon les termes de la licence Creative Commons Attribution - Pas d'Utilisation Commerciale - Pas de Modification 4.0 International. 


\title{
DUALISMO ESTRUCTURAL ANDINO Y ESPACIO NOVELESCO ARGUEDIANO
}

\author{
Edmer CALERO DEL MAR*
}

\section{Resumen}

A la luz de los principios dualistas estructurales andinos yanantin y masintin, evidenciados a partir de los años setenta, se propone un estudio del espacio en las novelas de José María Arguedas y en particular en Yawar fiesta. Se utiliza en esta novela el principio de relación complementaria geográfica y social, yanantin, para explicar los diferentes orígenes atribuidos al toro Misitu y el comportamiento de las comunidades con él. El principio masintin implica identidad, solidaridad y equivalencia entre los miembros que une. Se utiliza la combinación de dichos principios para proponer una explicación de la dinámica de las "batallas rituales" de las que el Pukllay es una modalidad. Se enfoca Yawar fiesta, en la que el Turupukllay está representado, utilizando esta interpretación.

Palabras claves: Batallas rituales, espacio novelesco arguediano, dualismo estructural andino, masintin, Misitu, Pukllay, Turupukllay, yanantin.

\section{DUALISME STRUCTUREL ANDIN ET ESPACE ROMANESQUE ARGUÉDIEN}

\section{Résumé}

À la lumière des principes dualistes structuraux andins yanantin et masintin, mis en évidence à partir des années soixante dix, on propose une étude de l'espace dans les romans de José María Arguedas et en particulier Yawar fiesta. On utilise, dans ce roman, le principe de relation complémentaire géographique et social, yanantin, pour expliquer les différentes origines attribuées au taureau Misitu et le comportement des communautés à son égard. Le principe masintin implique identité, solidarité et équivalence entre les membres qu'il unit. La combinaison de ces deux principes est utilisée pour proposer une explication de la dynamique des "batailles rituelles" dont le Pukllay est une modalité. On met l'accent sur Yawar fiesta, où le Turupukllay est représenté, en utilisant cette interprétation.

Mots clés : Batailles rituelles, espace romanesque arguédien, dualisme structural andin, masintin, Misitu, Pukllay, Turupukllay, yanantin.

\section{ANDEAN STRUCTURAL DUALISM AND ARGUEDIEN NOVELISTIC SPACE}

\section{Abstract}

A study of the fictional space of the novels of José María Arguedas, in particular Yawar Fiesta, is proposed in terms of the dual Andean structural principles, yanantin and masintin,

* Centre de Recherches Ibériques et Ibéro-Américaines de l'Université de Paris-X Nanterre, Bat. F. 358 - $3^{\circ}$ étage - 200, av. de La République, 92000 Nanterre Cedex, Francia. 
which have been recognized since the 1970's. In this novel, the principle of géographic and social complementary relationship, yanantin, is used to explain the different origins attributed to the bull, Misitu, and the way the different communities respond to him. The masintin principle implies identity, solidarity and equivalency between the members that it unites. The combination of these principles is utilized to propose an explanation of the dynamics of the "ritual battles", of which the Pukllay is one type. Yawar Fiesta and the Turupukllay, represented in this novel, are brought into focus using this interpretation.

Key words: Ritual battles, Arguedian novelistic space, Andean structural dualism, masintin, Misitu, Pukllay, Turupukllay, yanantin.

Desde hace algunos años, se considera que el espacio participa en la elaboración de la historia o trama que propone la novela y que llega a ser un "lugar generador de sentido". El espacio en las novelas de José María Arguedas, siendo considerado un espacio mítico (Rouillón, 1967; Forgues, 1989; Álvarez Arocha, 1989) y sagrado, engendra prohibiciones y obligaciones. Nuestro objeto de estudio es, entonces, una "geografía mítica", sagrada y que es, al mismo tiempo, funcional en las novelas de Arguedas. En este artículo nos ocuparemos solamente de un aspecto de dicha "geografía": el dualismo estructural andino. Los principios dualistas andinos yanantin y masintin están sobre todo presentes en la novela Yawarfiesta publicada en 1941, pero incluiremos también en nuestro estudio Los ríos profundos, de 1958 y Todas las sangres, de 1964 (1). ¿Cuál será la significación mítica de las oposiciones alto/bajo y zona quechua/zona puna omnipresentes en Yawar fiesta? La oposición dualista prehispánica alto/bajo que figura en los documentos de los cronistas de los siglos XVI y XVII, como El Inca Garcilaso o Cristóbal de Molina (del Cusco), deja ambigüedades en cuanto a la jerarquía de las comunidades e individuos ligados por dicha oposición. Los estudios realizados en el pueblo de Yucay (Molinié Fioravanti, 1985) y la puesta en evidencia del principio yanantin dejan ver que la oposición alto/bajo incluye también la oposición zona quechua/zona puna. La diversidad religiosa de los habitantes de esas zonas puede explicar en la novela Yawar fiesta los diferentes orígenes atribuidos al toro Misitu. Para unos es un illa o ser mítico capaz de perderse y vivir en lo profundo de las aguas de los lagos. Para otros es un salqa o simple animal salvaje suceptible de ser cazado y utilizado como objeto sacrificial de la herranza, rito de marcación del ganado.

El principio masintin rige, entre otras, las relaciones paternales, maternales y fraternales entre individuos del mismo sexo y no implica jerarquía preestablecida como el principio yanantin, que rige esas mismas relaciones pero entre individuos de sexo opuesto. Los textos quechuas de algunas canciones recogidas durante las batallas rituales, de las que el Pukllay es una modalidad, dejan ver la relación masintin que liga a los grupos que se enfrentan. Un criterio importante para la determinación del vencedor anual de dichas batallas es el número de muertos y el derramamiento de sangre. En ciertas zonas andinas, como en Ayacucho, se asocia la sangre al agua, que es regulada

(1) Emplearemos las Obras completas de la Editorial Horizonte, Lima, 1983, tomos II, III y IV repectivamente. 
en parte por los dioses montañas o Wamanis. Estudios etnólogicos y literarios han demostrado que, en pleno siglo XX, el pueblo de Puquio, en el departamento de Ayacucho, presenta divisiones sociogeográficas derivadas del dualismo estructural andino prehispánico. Se han constatado las relaciones fraternales que unen a las comunidades de Qollana y Chaupi por una parte y a las de K'ayau y Pichk'achuri por otra parte. Se ha constatado también que la división alto/bajo interviene entre las cuatro comunidades: Chaupi y Pichk'achuri están situadas arriba con respecto a Qollana y K'ayau, ubicadas abajo. Se ha demostrado también el alto grado de autenticidad de dicho pueblo en la novela Yawar fiesta. En esta novela, el deseo reiterado de las comunidades de K'ayau y de Pichk'achuri de vencer en el Turupukllay anual, que implica un enorme derramamiento de sangre humana o "agua", permite relacionar al Turupukllay con el Pukllay de las batallas rituales en las que el hombre, al sangrar, incita al Wamani a hacer lo propio. Al establecer esta relación surge el problema de la preeminencia si se tiene en cuenta, como hemos visto, que una de las comunidades que se enfrentan, K' ayau, comparte su calidad de "abajo" con la comunidad de Qollana, cuyo nombre implica preeminencia, superioridad, aspecto que la Historia de Puquio confirma. La comunidad de K'ayau situada también abajo debería ser, entonces, de manera constante superior a la de Pichk'achuri. Si la jerarquía ya está establecida, ¿por qué este deseo de competir? Nos encontramos, así, en una situación algo similar a la descrita por Molina y Garcilaso: enfrentamientos anuales de poblaciones hermanas, opuestas por la división alto/bajo, que deben ser iguales pero que, al mismo tiempo, debe "tenerse en memoria" la superioridad de una de ellas. La hipótesis de dos tipos de preeminencia permite resolver esta contradicción. La primera, basada en el principio yanantin que implica una jerarquía constante asociada a la oposición alto/bajo, explicaría la preeminencia constante de la comunidad de Qollana. La segunda, basada en el principio masintin que implica equivalencia y reciprocidad, se establece gracias a enfrentamientos anuales como el Pukllay y su versión metamorfoseada y sincrética: el Turupukllay. En Yawar fiesta, la gran relación social contradictoria, generadora de la acción novelesca, parece ser principalmente el establecimiento de la jeraquía masintin.

En los años setenta se han evidenciado dos principios organizativos del espacio andino: el yanantin y el masintin. ¿Cómo ha utilizado Arguedas esos principios?

\section{YANANTIN}

Núñez del Prado (1979: 5) explica así esta noción:

"Entiendo por Yanantin el principio de oposición complementaria a través del cual el hombre andino ve su universo y organiza su mundo en parejas de opuestos complementarios, todo lo que en él se encuentra. Estos opuestos complementarios son asociados a las nociones de 'masculino' y 'femenino', son interdependientes, jerarquizados y unidos entre sí por una cadena de intercambios recíprocos de diferente naturaleza y/o asimétricos."

Enrique Mayer (1977: 77) aclara:

"El concepto yanantin del que Tristan Platt tomó conciencia en un trabajo de campo en una comunidad quechua de Bolivia me fue explicado primero 
por él (comunicación personal). Según Platt (2), las cosas que al reflejarse en un espejo son iguales unas a otras están en una relación yanantin; por ejemplo la mano izquierda y la derecha son iguales solamente en una relación de imagen de espejo. El marido y la mujer están también conceptualizados en una relación yanantin."

A partir de esas definiciones se puede deducir que para los andinos el universo se compone de pares de elementos complementarios y opuestos; estando dichos elementos ligados por una relación yanantin que es comparable a la que liga un objeto a su imagen en un espejo. Se dan varios ejemplos de parejas: mano derecha/mano izquierda, marido/mujer, masculino/femenino. Según Daisy Núñez del Prado, los elementos de dichas parejas están jerarquizados.

A nivel mítico, una ilustración de este principio es la fundación de la ciudad del Cusco y el establecimiento de la pareja fundadora según el Inca Garcilaso de la Vega (1973: 49):

"Desta manera se principió a poblar esta nuestra imperial ciudad, dividida en dos medios, que llamaron Hanan Cozco, que como sabes quiere decir Cozco el alto, y Hurin Cozco, que es Cozco el bajo. Los que atrajo el Rey quiso que poblasen a Hanan Cozco, y por eso le llamaron el alto, y los que convocó la Reina que poblasen a Hurin Cozco, y por eso le llamaron el bajo. Esta división de ciudad no fue para que los de la una mitad se aventajasen de la otra mitad en esenciones y preminencias, sino que todos fuesen iguales como hermanos, hijos de un padre y de una madre. Sólo quiso el Inca que hubiese esta división de pueblo y diferencia de nombres, alto y bajo, para que quedase perpetua memoria de que a los unos había convocado el Rey y a los otros la Reina. Y mandó que entre ellos hubiese sola una diferencia y reconocimiento de superioridad: que los del Cozco alto fuesen respetados y tenidos como primogénitos, hermanos mayores, y los del bajo fuesen como hijos segundos; y en suma, fuesen como el brazo derecho y el izquierdo en cualquiera preminencia de lugar y oficio, por haber sido los del alto atraídos por el varón y los del bajo por la hembra."

En esta cita de Garcilaso, una serie de elementos se presentan por pares:

$\begin{array}{ll}\text { Rey } & \text { Reina } \\ \text { Varón } & \text { Hembra } \\ \text { Hanan, alto } & \text { Hurin, bajo } \\ \text { Primogénitos } & \text { Hijos segundos } \\ \text { Brazo derecho } & \text { Brazo izquierdo }\end{array}$

Cada elemento de la columna de la izquierda parece ligado al de la derecha por una relación yanantin. El brazo derecho o lo alto pueden tener una pareja simétrica con

(2) Tristan Platt desarrolla estos conceptos en un artículo publicado en castellano (1976) — que citaremos luego-y en otro publicado en francés (1978). 
relación a un eje en el brazo izquierdo o lo bajo, como una imagen en un espejo. Esta relación yanantin entre lo alto y lo bajo e inclusive entre la puna y el valle ha sido evidenciada por Tristan Platt (1976: 8-9) que especifica que esta última oposición, basada solamente en parte en la geografía, tiene repercusiones en toda la organización social:

“... en términos conceptuales esta discontinuidad [puna/valle], que en la naturaleza se presenta en forma imprecisa, se hace mucho más precisa a través de todo un conjunto de conceptos y creencias, con lo que ya puede convertirse en un principio regulador de la organización social."

Asimismo si, como lo supone Platt, el hombre y la mujer se sitúan en una relación yanantin uno con relación al otro, es lógico que el rey o la reina o que los elementos varones y hembras lo estén también. En el texto de Garcilaso ese lazo se hace también extensivo a la relación entre los primogénitos y los hijos segundos. Hay sin embargo una paradoja en lo que se refiere a la igualdad de los elementos de cada pareja. En el texto se lee que:

"Esta división de ciudad no fue para que los de la una mitad se aventajasen de la otra mitad en esenciones y preminencias, sino que todos fuesen iguales como hermanos, hijos de un padre y de una madre..."

Esto corresponde a la igualdad de los elementos de un mismo par. En cambio, acto seguido, hay de modo evidente una jerarquía entre los elementos de un mismo par, ya que todos los elementos de la columna de la derecha deben reconocer la superioridad de los de la izquierda. Esta jerarquía la recalca igualmente Daisy Núñez del Prado como hemos visto. Platt (1976: 49) llega a una conclusión similar estudiando a los Macha y constata que hay una ambigüedad en la relación yanantin:

"Yanantin puede indicar una pareja de simetría e igualdad perfecta, pero también puede servir como disfraz ideológico para una relación que en realidad es desigual, como la que existe entre el Hombre y la Mujer."

Dos preguntas surgen a este nivel. Existían relaciones de fraternidad entre el Alto y el Bajo Cusco pero, ¿existía o no una jerarquía entre las dos partes de la ciudad y de qué naturaleza era esa "superioridad"? Volveremos sobre la importancia de estas relaciones y sobre su complejidad en la obra novelesca de Arguedas cuando hagamos intervenir otro principio para explicarlas, el masintin.

Así, el principio yanantin puede permitirnos explicar la división alto/bajo presente aún en numerosos pueblos andinos como Yucay (3), en el departamento del Cusco y Puquio (escenario de la novela Yawar fiesta) en el departamento de Ayacucho.

Arguedas (1974: 165) escribe:

"Yawar fiesta es la novela de los llamados 'pueblos grandes', capitales de provincia de la "sierra"".

(3) Molinié Fioravanti(1985: 98): "Yucay sigue dividido hoy en dos mitades como antiguamente: Huichayparte (wichay: arriba) y Urayparte (uray: abajo). La iglesia arriba y el cementerio abajo marcan los límites del espacio del pueblo." 
Puquio, donde tiene lugar gran parte de la acción de la novela Yawar fiesta, ha sido objeto de un estudio comparativo como ciudad real, histórica y como espacio ficcional de dicha novela (Pratlong, 1982). Se ha demostrado así que la estructura de Puquio está calcada de la estructura del Cusco incaico:

"En Puquio [...] como en el Cusco existe entre las dos mitades una analogía de estructura en la medida en que desde el punto de vista topográfico, hidrológico y jerárquico, Qollana es para Chaupi lo que Qayau es para Pichk'achuri, asimismo en el Cusco, Chinchaysuyu (Qollana) es para Antisuyo (Payan) lo que Collasuyu (Qayao) es para Cuntisuyu. En Puquio, a Qollana y a K'ayau se les llama uraypi en comparación con Chaupi y con Pichk'achuri, ambos hanaypi [...] Mutatis Mutandis, la estructura de Puquio parece, entonces, haber sido calcada de la del Cusco incaico." (Pratlong, 1982: 36-38)

Arguedas (1956: 184-185) señala los estrechos lazos fraternales que unen a las comunidades:

“Los ayllus de Chaupi y Qollana se consideran 'hermanos', así como Qayao y Pichqachuri, entre sí."

Hemos visto, entonces, que las similitudes entre la organización de Puquio y la del Cusco incaico comprenden tanto la distribución espacial como las relaciones sociales existentes entre las dos ciudades.

Núñez del Prado (1979: 2), tanto como Platt, recalca que la noción yanantin está presente también en la división puna/valle, a la que corresponde la oposición puna/ quechua descrita por Molinié Fioravanti (1985: 108) en un estudio realizado en el mencionado pueblo de Yucay:

"La distinción entre quechua y puna es una de las formas de la oposición más general [...] entre las categorías de abajo y de arriba, oposición fundamental en la cosmogonía indígena de los campesinos de abajo. Arriba en el cerro están las fuerzas maléficas que se deben conjurar y los poderes sobrenaturales que hay que conciliarse."

Esta cita muestra que la puna es un lugar hierofánico importante. La oposición quechua/puna tiene, entonces, dos dimensiones: una geográfica y una divina.

Veamos primero cómo la descripción construye, en la novela Yawar fiesta, el espacio correspondiente a la sierra peruana. En el principio de la novela, "el medio transparente" (4) utilizado es "el abra de Sillanayok". A partir de este lugar, el personaje focalizador, el viajero, nos hace descubrir el pueblo de Puquio con tres de sus cuatro ayllus (Arguedas, 1983[1941]: 71). En el segundo párrafo, utilizando el mismo lugar, se introduce en el relato la puna, zona del paisaje serrano (5) muy importante en la novela:

(4) Tomando ejemplos de la obra novelesca de Zola, Hamon (1972: 473) considera entre los temas necesarios a la descripción les milieux transparents: las ventanas, las puertas abiertas, los panoramas extensos, etc.

(5) Weberbauer (1945: 83): "El piso más alto de la Sierra, exento de agricultura, se denomina Puna en el sur y centro del país y Jalca en el norte." 
“Desde el abra de Sillanayok' se ven tres riachuelos que corren [...] Los riachuelos bajan de las punas corriendo por un cauce brusco, pero se tienden después en una pampa desigual donde hay hasta una lagunita; termina la pampa y el cruce de los ríos se quiebra otra vez y el agua va saltando de catarata en catarata hasta llegar al fondo de la quebrada." (Arguedas, 1983[1941]: 71)

Dos elementos son, de esta manera, introducidos simultáneamente en el principio de Yawar fiesta, la puna y las comunidades, lo que podría ser el primer índice de la igualdad de su importancia en el mundo ficcional de dicha novela. La puna está caracterizada por un clima y un ambiente particulares. Es el lugar donde viven los punarunas (6) y un lugar de paso para los viajeros. He aquí cómo la perciben ambos:

"En la puna alta, bajo el cielo nublado, en el silencio grande; ya sea cuando el aguacero empieza y los truenos y las nubes negras asustan y hacen temblar el corazón; ya sea cuando en el cielo alto y limpio vuelan cantando las k'ellwas y los ojos del viajero miran la lejanía pensativos ante lo grande del silencio; en cualquier tiempo, esas chukllas [choza en nota al pie] con su humo azul, con el ladrido de sus chaschas [perro pequeño en nota al pie], con el canto de sus gallos, son un consuelo para los que andan de paso en la puna brava." (Arguedas, 1983[1941]: 78)

Es, sobre todo, gracias a la vegetación que Arguedas construye dicho piso ecológico. Dos plantas que caracterizan fuertemente la zona puna, Polylepis queñoa o k’eñwa (7) y el ichu (8) están presentes:

"En el claro del k' eñwual el ischu es amarillo y alto, duro. Parece como que la luz del día llegara primero allí; apenas alumbra el alba, el ischu amarillo se ilumina" (Arguedas, 1983[1941]: 160).

El piso ecológico más alto de la sierra, la puna, queda así mencionado por su nombre y caracterizado por su vegetación. No ocurre lo mismo con las zonas contiguas. En su estudio sobre Puquio, Arguedas (1956: 203) escribe en una nota al pie:

"Moya. Zona intermedia entre la puna y las tierras cultivables de clima templado (qeshwa). Las moyas son ricas en pastos."

Si las zonas inferiores, moya y quechua (qeshwa en la cita), no están mencionadas por su nombre, se las puede identificar gracias a la presencia de una planta considerada por los botanistas como indicador natural de esos pisos ecológicos, el molle (9):

(6) "Punarunas. Gente de la puna." (Arguedas, 1983[1941]: 78, nota al pie).

(7) Weberbauer (1945: 394) especifica: "Montes de Polylepis ('Quinuales'). Se encuentran dispersos en uno que otro lugar de la Puna, principalmente en la parte occidental de ella, entre los 3700 y $4500 \mathrm{~m}$. de altura, subiendo hasta la nieve persistente [...] En estos montes el género Polylepis está representado por varias especies poco distintas unas de otras. Su forma es ya de un arbusto ya de arbolillo, llegando su alto hasta cinco m."

(8) Weberbauer (1945: 391): "La formación de las Gramíneas dispuestas en manojos aislados (pajonal de Puna). Es entre las formaciones altoandinas la más extensa.[...] Todas estas Gramíneas altas llevan el nombre de ichu en el idioma quechua."

(9) Weberbauer (1945: 175): “Anacardiaceae. Un porte particular, difícil de olvidar, una gran frecuencia y una distribución limitada por líneas divisorias fundamentales de la vegetación peruana, 
"Junto a la pared del corral, junto a la casa, o al centro del patio, un molle frondoso que hace sombra por las mañanas y en las tardes; sobre el molle suben las gallinas al mediodía y dormitan, espulgándose." (Arguedas, 1983[1941]: 72)

Además, el enfoque que se hace de esas zonas no es homogéneo, las zonas moya y quechua quedan confundidas. La oposición es, pues, entre la puna (10) y las dos zonas inferiores (moya y quechua).

Hay, entonces, la voluntad de construir un mundo en el que la oposición alto/bajo está presente gracias a los pisos de la vegetación y a las características climatológicas de dos zonas importantes en Yawar fiesta: la zona puna y la zona quechua. ¿Qué sucede en las otras novelas? En Los ríos profundos, la puna aparece apenas evocada gracias a los recuerdos de Ernesto:

"En Huancapi estuvimos sólo unos días.[...] En la falda de los cerros el viento sacude la paja; en el lecho de la quebrada y en algunas hondonadas crece la k'eñwa, un árbol chato, de corteza roja. La montaña por donde sale el sol termina en un precipicio de rocas lustrosas y oscuras. Al pie del precipicio, entre grandes piedras, crecen también esos árboles de puna, rojos." (Arguedas, 1983[1958]: 31)

La zona puna no se opone a la zona quechua.

En Todas las sangres, una catalogación de la flora nos hace llegar, solamente en las cavilaciones de uno de sus personajes a la puna, a 4200 metros, altura máxima que permite el cultivo de papas (11) que son amargas (12):

"Convirtieron en brutos a los indios para que reináramos nosotros. Tuvieron que dejar que se perdieran esos andenes porque costaba mucho cuidado y vigilancia mantenerlos, y los indios tenían que ser arreados a la altura a comer papa amarga y mashua que les conservaba la fuerza y les apagaba la luz de la razón.” (Arguedas, 1983[1964]: 200-201)

dan a Schinus molle el valor de un elemento importantísimo e indicador en la geografía botánica del país. Los habitantes dan el nombre de "molle' a este arbusto o arbolillo [...] El límite de su extensión vertical oscila alrededor de los $3300 \mathrm{~m}$. en el Sur, $3000 \mathrm{~m}$. en el Centro y los $2000 \mathrm{~m}$. en el Norte."

(10) Flores Ochoa (1974-1976: 246) describe el pastoreo en la puna alta lo que implica una puna baja, pero los dos pisos que él menciona están incluidos en el habitat de los montes de Polylepis, quinuales o k'eñwales: "El pastoreo de la alta puna [...] Entre los 3800 y los 4000 metros hay comunidades de agricultures de tubérculos altoandinos, con ganadería basada en ovinos y también camélidos. Entre los 4000 y los 4200 y 4300 metros las comunidades son de pastores de ovinos y camélidos con algo de cultivo, limitado a veces a sólo papas y a partir de estas alturas, según las regiones, se comienzan a presentar únicamente comunidades de pastores de camélidos." En lo sucesivo, solamente hablaremos de la puna.

(11) Weberbauer (1945: 624): "En la región donde se tocan los departamentos de Puno y Cuzco por ejemplo, se nota que el cultivo de la papa sube hasta los $4200 \mathrm{~m}$. Parece que allí, la gran densidad de la población obliga a los pequeños agricultores a explotar hasta la últimas posibilidades."

(12) Beyersdorff (1984: 36): "Haya papa. Papa amarga cosechada en la zona Puna, que se utiliza en la elaboración de la muraya." 
En Todas las sangres, contrariamente a lo que sucede en Yawar fiesta, la zona moya está explícitamente citada e incluso definida:

"En las moyas de la hacienda Providencia residían todos los colonos de los Aragón de Peralta. Se llamaban moyas en esa región del Perú a las tierras de pasto de la zona fría, próxima a los nevados." (Arguedas, 1983[1964]: 37).

Esta definición difiere de lo que se llama moya en la zona de Puquio, descrita por Arguedas.

Una explicación posible sería que la palabra moya cubra dos nociones diferentes en función de las regiones. En Todas las sangres solamente la zona quechua está verdaderamente descrita.

En resumen, la opción escogida por Arguedas ha sido la de privilegiar las zonas puna y quechua, evocadas gracias a las características de las formaciones vegetales en función de los pisos ecológicos, en detrimento de la zona moya. ¿Cuál o cuáles puede o pueden ser la o las funciones de esa opción? ¿Por qué la descripción de esas zonas toma tanta importancia en Yawarfiesta en comparación con la que toma en Los ríos profundos y en Todas las sangres? Las relaciones entre esas dos zonas regidas, por lo menos parcialmente por uno de los principios andinos de la oposición complementaria, el yanantin, dejan presagiar la emergencia de una acción. ¿Cómo va a materializarse dicha acción?

A esta oposición geográfica alto/bajo o zona puna/zona quechua debería juxtaponerse una oposición religiosa de esas dos zonas según Molinié Fioravanti. ¿Qué sucede en Yawar fiesta, Los ríos profundos y Todas las sangres?

En Yawar fiesta, el elemento que permite ilustrar mejor esta oposición es el mito del Misitu y sus implicaciones. Eso hace que se diferencie la gente de K' ayau (de la zona quechua) de la de K' oñani (de la zona puna) que actuarán simultáneamente en dos planos paralelos y así lo harán hasta el final. Hay que recalcar igualmente que, por sus habitantes y creencias, una de las comunidades de Puquio, Pichk' achuri, es más allegada que las otras a la zona puna, y por ende, a la gente de K'oñani:

“Los pichk' achuris fueron siempre verdaderos punarunas. Los otros ayllus también tenían estancias y comuneros en la puna, pero lo más de su gente vivía en el pueblo; tenían buenas tierras de sembrío junto a Puquio, y no querían las punas, casi les temían, como los mistis. Pichk'achuri era, y ahora sigue siendo, ayllu compartido entre puquianos y punarunas." (Arguedas, 1983[1941]:79)

Es interesante, primero, comparar el origen que cada una de las dos comunidades le atribuye al Misitu. El narrador omnisciente nos hace saber las circunstancias reales de la aparición del Misitu, que escapándose de una estancia llega a la puna de K’oñani (13):

(13) Chipau, pueblo del layk'a que morirá atacado por el toro Misitu, está situado también en la puna: “¡Ahistá el K’arwarasu! —hablan—. ¡Qué grande había sido! ¡Qué imponente! Entonces el arriero o el guía dice señalando: [...] y al pie mismo del pico del medio, casi donde empieza la nieve, está Chipau." (Arguedas, 1983[1941]: 152) 
"Llegó a las punas de K'oñani ya toro, escapando de otra estancia; quien sabe de Wanakupampa, de Osk'onta, o de más lejos. Apareció de repente en los k'eñwales de Negromayo. Y desde entonces los punarunas no se acercaron a la quebradita del Negromayo, por el lado de K' oñani." (Arguedas, 1983[1941]: 136)

Por este hecho, el Misitu es temido como salqa. El nexo entre la puna y el Misitu es explícito, por lo menos en quechua, ya que salqa significa también puna (14). Además, la toponimia escogida para los lugares probables de su procedencia, Wanakupampa y Osk'onta, va en el mismo sentido ya que esas dos palabras están formadas a partir de nombres de animales salvajes que habitan en la puna: el guanaco y el osk'o (15). De esta manera, la puna, como lugar de residencia, le imprime al Misitu algunos de sus caracteres lo que nos permite entender mejor la nota que Arguedas pone al pie de página:

"Sallk'a. Salvaje. Se da este nombre a los toros montaraces." (Arguedas, 1983[1941]: 90)

Para la gente de la comunidad de K' ayao, el Misitu es un simple salqa:

“- Ahura K’ayau va echar Misitu de don Jolián en plaza. ¡Mentira encanto! Sallk'a grande no más es Misitu, enrabiado hasta corazón. Por eso queriendo para turupukllay." (Arguedas, 1983[1941]: 91)

Arguedas atribuye a la gente de K' oñani, comunidad de la puna, otro punto de vista. El layk'a Kokchi, uno de sus miembros, se dirige así a la montaña Ak'chi, dios tutelar de la comunidad:

“Desde tu cumbre estás viendo Torkok'ocha, tu laguna; de allí es Misitu, de su adentro, de su agua, ha despertado tu animal. Aquistá tus k'oñanis, han venido en la noche, caminando lejos, en helada, en el frío, en el viento, para avisarte, rabia de Kayau quiere Misitu" (Arguedas, 1983[1941]: 139)

Torkok'ocha es una laguna de la puna. Las circunstancias en las que el Misitu emerge de dicha laguna se parecen a las de la leyenda El toro encantado que describe la emergencia de un toro mítico de la laguna Rasuhuillca (16). Cuando los representantes de la comunidad de K'ayao se dirigen al de Koñani para convencerle de que les dejen capturar al Misitu, le dicen que otro toro saldrá del agua:

(14) Soto Ruiz (1976): "Sallqa. sustantivo. Puna, partes altas de la cordillera." Recordemos que Puquio forma parte del departamento de Ayacucho, zona incluida en este diccionario.

(15) Wanakupampa viene de guanaco, wanaku en quechua, clasificado como salqa por Flores Ochoa (1974-1976: 256.) y de pampa. Osk'onta, de: "Osjo. Gato montés de la puna y de la selva" [...]. "Oskollo. Como: Osjo, osjollo." (Chouvenc \& Perroud, 1970) y de la partícula: "nta= por, por entre", Guardia Mayorga (1973: 301).

(16) Arguedas \& Izquierdo Ríos (1947: 82-83): "La tradición huantina dice que dentro de esta laguna [Rasuhuillca] se encuentra un toro negro [...]. Hace muchos años, el toro logró vencer a la anciana y salió a la superficie; e inmediatamente las aguas de la laguna se embravecieron y rompieron los diques con grandes oleajes, inundaron Huanta, arrasaron con toda la población produciendo grandes estragos; entonces, los indios de la altura, al darse cuenta de ésto, procedieron rápidamente a echar lazo al toro y lo hundieron nuevamente." 
“Pero el varayok' alcalde y el layk'a le hablaron despacio al mayordomo de la estancia [...] Que era voluntad del auki que el Misitu jugara en Pichk' achuri. Que un toro k'osñi iba a salir de Torkok' ocha, en reemplazo del Misitu para los k'oñanis." (Arguedas, 1983[1941]: 158)

193) escribe:

¿Qué representa entonces el Misitu para la gente de la puna? Arguedas (1987c:

“... son illas los toros que habitan en el fondo de los lagos solitarios, de las altas lagunas rodeadas de totora, pobladas de patos negros. Todos los illas causan el bien o el mal, pero siempre en grado sumo."

En Yawar fiesta, ¿el Misitu de la gente de la puna podría ser un illa? Varios elementos de respuesta se encuentran en la novela. Cuando los pastores se dirigen a los illas (17) o amuletos les pueden llamar:

“niñacha, mamacha, 'niñita, señorita, madrecita' o también papay, tatala, machula, hayñachu, 'padre, abuelo padrillo'." (18)

En Yawar fiesta, Kokchi se dirige al Misitu llamándole de la misma manera: “¡Papay! ¡Papacito!” (Arguedas, 1983[1941]: 177)

Entre las fuerzas sobrenaturales de la puna y sus hierofanías, Flores Ochoa (19741976: 250) cita, además de las illas, los enqas, los enqaychus y los khuya rumis y precisa que:

"Estos conceptos y objetos parece que sintetizan de manera simbólica la relación que hay entre los pastores de la puna alta y los mundos natural y sobrenatural que forman parte de su medio ambiente. Son los intermediarios a través de los cuales se vinculan con lo natural y lo sobrenatural."

Solamente estudiaremos los tres primeros porque son importantes para explicar la ambigüedad del Misitu. Veamos primero el enqa:

“Enqa es el principio generador y vital. Es la fuente y el origen de la felicidad, el bienestar y la abundancia. No está directamente representado por objetos físicos naturales ni tiene visualización en los objetos que conforman el señalu q'epi (19) aunque como principio está presente de manera permanente en él, porque sin su intervención no habría posibilidad de que el ganado se conservara con bienestar y pudiera multiplicarse. Es por estas razones que los pastores dicen que las illa y los enqaychu también son enqa y que ‘tienen’ enqa.” (Flores Ochoa, 1974-1976: 250)

(17) Flores Ochoa (1974-1976: 249): "Las illa son pequeñas esculturas que representan alpacas, llamas u ovejas. Son de piedra, por lo general de cuarcita, basalto, granito, u otras piedras de grano fino. Muchos sin lugar a dudas son de origen precolombino, de las que se conocen en forma difundida como conopa. Veremos luego que cuando el enqa se manifiesta en forma de alpaca, esta última se transforma en piedra y desaparece cuando la gente se acerca, dejando en su lugar piedras que llegan a ser amuletos."

(18) En lo que se refiere al sexo de los illas, Flores Ochoa (1974-1976: 253) recalca que: "Son asexuales, o tal vez bisexuales, porque pueden ser machos como hembras; aunque no simultáneamente."

(19) "Es un atado en el que se guardan los objetos sagrados que se utilizan en las ceremonias ganaderas de propiciación y fertilidad.” (Flores Ochoa, 1974-1976: 248) 
Este principio puede, entonces, materializarse en las illas y en los enqaychus, que son amuletos encontrados en circunstancias particulares:

"Se los busca de manera expresa, pero será en última instancia el destino, que es la misma enqa, el que los ponga a disposición de la persona que sale en pos de ellos." (Flores Ochoa, 1974-1976: 251)

Tanto los enqaychus como las illas pueden tener la figura de una alpaca (20) pero se señala que:

"Hay enqa para alpacas, llamas, para ovejas, para vaca también, pero no hay para caballos ni otros animales." (Flores Ochoa, 1974-1976: 252)

Se busca el enqa durante la temporada de lluvias o el primero de agosto:

"En los meses de enero, febrero y marzo es cuando se los busca. [...] Otro día bueno para buscar enqa es el primero de agosto." (Flores Ochoa, 1974-1976: 251)

En Yawarfiesta, la captura del Misitu tiene lugar el 27 de julio, o sea, algunos días antes del primero de agosto.

La oposición entre las zonas puna y quechua está presente durante toda la caza del Misitu. La primera etapa es la solicitud hecha al K' arwarasu por las dos comunidades para obtener el permiso de capturar al Misitu. El K'arwarasu responderá a los representantes de las dos comunidades de manera opuesta. Así, el layk'a de Chipau (zone puna) debe coger solo al Misitu:

“El layk'a quería ir solo por el Misitu; decía que el tayta K'arwarasu le había dado poder sobre los toros de todas las punas que pertenecen al auki." (Arguedas, 1983[1941]: 153)

La respuesta obtenida por el varayok' alcalde de K'ayau (zone quechua) es contraria, ya que a él deberá acompañarlo toda la comunidad:

"Pero el varayok' alcalde [...] dijo que el taita le había ordenado a él ir con todo el ayllu." (Arguedas, 1983[1941]: 153)

Arguedas indica que el layk'a de Chipau (zona puna) tiene solamente un lazo para sujetar las llamas y que no trata de utilizarlo, que no lleva poncho (está, entonces, pobremente vestido) y que encara al Misitu solo, luego de pedir tranquilidad a los presentes:

“El layk'a se paró a distancia de los árboles, en el claro del k'eñwal. Llevaba un lacito de llama; no tenía poncho estaba solo.

$[\ldots]$

- ¡Toro, toro! ¡Misitu! ¡Está corriendo!

- ¡Está viniendo!

(20) "Se ve que los enqaychu tienen enqa y son llamados también enqa justamente porque son la señal que se les presenta a los 'pobres' que la buscan. [...] Pueden tener la figura de una paqocha (alpaca) pero en la mayor parte de las veces son más bien piedras brillantes y pulidas no talladas, sin figura que pretenda semejar animales. Las illa son representaciones de las paqocha (alpacas) de los rebaños." (Flores Ochoa, 1974-1976: 252) 
El layk'a se volteó a ese lado; levantó su brazo, como pidiendo tranquilidad." (Arguedas, 1983[1941]: 160)

En cambio, toda la gente de la comunidad de K' ayau (zone quechua) está presente y va vestida como para asistir a una fiesta:

"Iban como resbalando, agachados, pisando con cuidado sobre el waylla ischu, Negro se veía, entre el pajonal de la quebradita, los ponchos azules de los k'ayaus y la bayeta oscura de sus waras. Como en media legua del pajonal se extendían, y fueron acercándose, despacito, como creciendo, hacia los k'eñwales." (Arguedas, 1983[1941]: 160)

Llevan lazos que preparan para capturar al Misitu:

"Trepaban a las ramas, desenrollaban el lazo y lo preparaban como para tirarlo desde lejos." (Arguedas, 1983[1941]: 160).

Además, hacen mucho ruido:

“Cuando el último k’ ayau llegó al k’eñwal, todos gritaron, juntos, remeciendo la rama de los árboles. El layk'a seguía parado en el pajonal. Gritaron dos o tres veces, a un tiempo, comenzando por la tropa del varayok' alcalde." (Arguedas, 1983[1941]: 160)

La gente de la comunidad de K' ayau hace por lo tanto un Chaco (21) o caza de animales salvajes para capturar al Misitu, al que sólo considera un salqa.

¿Por qué los habitantes de la comunidad de K'ayau insisten en que el Misitu es un simple animal salvaje, un salqa, y en su deseo de capturarlo como tal?

En una de sus publicaciones sobre la herranza o marcación del ganado del área de Huamanga, de la que Puquio forma parte, Arguedas (30. XII. 1962: 8) escribe:

"Ofrecemos una síntesis del [rito de la marcación del ganado] que rige en el área de Huamanga: el ganado bravo es conducido al gran corral (cancha) mediante la influencia mágica de una melodía antiquísima que dos indios tocan en wak'rapukus".

En el cuento Yawar (Fiesta), considerado como una versión anterior de la novela Yawar fiesta (22), la llegada de los toros salvajes al pueblo para la hierra, otro nombre de la herranza (Arguedas, 1983[1935]: 79), se acompaña igualmente con música y cantos propios a esta ceremonia:

"La llegada de los toros levantaba polvareda en los caminos de entrada y producía revuelo y entusiasmo entre la indiada y los muchachos de la escuela. Todos los indios corrían a la entrada de sus respectivos barrios.

(21) Cobo (1956: 268-269) describe tres tipos de caza de los cuales el chaco, cerco humano que estrechándose permitía la captura o muerte de los animales salvajes, es el más común. Dicho autor insiste en el marco legal y colectivo de dicha actividad. Dans Dioses y hombres de Huarochirí (Arguedas, 1966: 66) el chaco está asociado a la pluviomagia.

(22) Rowe (1979: 30): “En 1937, Arguedas publicó en la Revista Americana de Buenos Aires un cuento titulado 'Yawar (Fiesta)'. Aunque en gran medida está redactado en la forma de un ensayo (por ejemplo, carece de personajes), puede tomarse en muchos sentidos como una versión anterior de Yawar fiesta." 
Las comisiones llegaban al pueblo tocando sus grandes cornetas de cuerno y cantando en coro las canciones de la hierra. En cuanto los toros ingresaban a la primera calle del barrio, toda la gente gritaba:

-¡Viva! ¡Viva toro! ¡Viva 28 de julio!” (Arguedas 1983[1937]: 122)

En la novela Yawar fiesta, la llegada del toro Misitu tiene lugar la víspera del 28 de julio, es decir, dentro del periodo de la celebración de la herranza de vacunos (Arguedas, 1953: 266), y se hace también al son de trompetas de cuerno de toro o wakawak'ras:

“Cuando llegaron a Yallpu, el Raura dio la señal con su wakawak'ra. Todos los corneteros tocaron de un golpe. El Misitu quiso encabritarse, pero le hicieron saltar el riachuelo, y lo arrastraron a carrera por el callejón de entrada al pueblo." (Arguedas, 1983[1941]: 175)

En la síntesis mencionada, Arguedas nos informa que el toro escogido es el más grande: "varios hombres echan lazo al más grande de los toros". En la novela, el toro escogido para el sacrificio es también el más grande:

"Miró [don Julián Arangüena] atrás, para ver al Misitu. Seguía persiguiéndole de cerca; su lomo parecía mecerse; se le veía como si fuese un toro del alto de una iglesia, porque se levantaba sobre el aire para saltar las matas del waylla." (Arguedas, 1983[1941]: 136)

A los otros toros solamente se les menciona:

“Anocheciendo, llegaron al abra de Pedrork'o. En la sombra, Puquio se veía grande. El ayllu K'ayau frente à Pichk'achuri, y en la plaza de Pichk'achuri, junto a la pared del coso, la placita del Vicario, como una especie de corralito de encerrar becerros; viéndolo, los k'ayaus se rieron. El coso estaba ya lleno de ganado; los otros ayllus habrían hecho llegar los toros bravos." (Arguedas, 1983[1941]: 163)

En Yawar fiesta, Arguedas menciona la palabra hierra solamente una vez y en un momento crucial de la corrida, el que precede al ingreso del Misitu al ruedo:

“El varayok' alcalde de K'ayau se levantó y dio la señal al regidor que estaba esperando la orden para hacer soltar al Misitu. [...] Las mujeres se callaron. Entonces los corneteros comenzaron a tocar el Jaykuy, la entrada; en tono delgado como canto de hierra. Los wakawak'ras llamaban, con voz de gente." (Arguedas, 1983[1941]: 190)

En la síntesis que venimos utilizando, Arguedas describe el sacrificio mismo:

"Han cavado mientras tanto una especie de sepultura en la puerta de la cancha. Arrastran al toro hacia el hoyo y lo tumban de espaldas. Entonces el pongo, sacerdote del Wamani, le abre el pecho con 'un puñal de castilla'; le extrae el corazón y lo arroja fuera del cerco. Mientras el toro aún brama, aparece un cóndor gris inmenso; baja hasta casi rozar las cabezas de los hombres y 'recoge' la ofrenda."

Tres aspectos del sacrificio se evocan en la novela: el toro debe vivir aún un poco después de la extracción del corazón, un ave teofánica debe llevarse la ofrenda y el 
Wamani, dios montaña, debe estar presente de alguna manera. El pecho del animal debe quedar abierto sin que la muerte sea inmediata:

"Un dinamitazo estalló en ese instante, cerca del toro.[...] El Misitu caminaba a pasos con el pecho destrozado; parecía ciego. El "Honrao" Rojas corrió hacia él.

-¡Muere, pues, muérete sallk'a!- le gritaba abriendo los brazos.” (Arguedas, 1983[1941]: 192)

En la síntesis dada por Arguedas, el cóndor, teofanía del Wamani, "recoge” el corazón. Se trata entonces de una ofrenda hecha a los Wamanis, lo que se confirma aún más por la presencia del sacerdote del Wamani. En Yawar fiesta las aves ak'chi sobrevuelan las montañas de los alrededores en los momentos que preceden al ingreso de los indios a la pequeña plaza donde tendrá lugar la corrida:

"Las rocas de la cumbre del Pedrork'o se mostraban color ceniza; junto a las rocas volaban varios ak'chis negros; y por eso la cumbre parecía más alta todavía y más lejana; los ak'chis daban vueltas, volando despacio, como buscando algo en el fondo de la quebrada." (Arguedas, 1983[1941]: 185)

Esta presencia se relaciona con dos hechos de la novela. En primer lugar, el Misitu vivía en la jurisdicción de la montaña Ak' chi (23). En segundo lugar, los espíritus de las montañas pueden tomar la forma de un ave cuando se les llama (Arguedas, 1956: 200). Se puede pensar, pues, que esta especie de gavilán (Chouvenc \& Perroud, 1970) es una teofanía, una manifestación del dios montaña Ak'chi que participará en el rito. En cuanto a las otras montañas, se ha dispuesto todo para que puedan ver el sacrificio sin ser impedidas por los graderíos de la pequeña plaza:

“¡Yastá, taita!- exclamó el alcalde de Pichk’achuri.

- Pero auki Pedrork'o, auki Sillanayok', capaz molestará; capaz graderío tapará su cumbre- replicó el de K'ayau.

- Bajo no más haremos cerco; mirarán alegres todas las cumbres, desde lo alto." (Arguedas, 1983[1941]: 151)

Gracias a un tipo de caza que corresponde a la de los animales salvajes, el chaco, la comunidad de K' ayau logra la captura del toro montaraz Misitu. El cotejo entre los principales elementos de la hierra o herranza de animales salvajes y la evocación de dichos elementos en la novela Yawar fiesta nos permiten entender la actitud de la comunidad de K'ayau. La necesidad, para la ejecución de dicho rito, de animales salvajes y en particular del más imponente, el Misitu, queda de este modo satisfecha. Finalmente, es gracias sobre todo a la toponimia que la puna, como parte del espacio ficcional, imprime en el Misitu su carácter salvaje o salqa, lo que lo convierte en objeto sacrificial para los integrantes de la comunidad de K'ayau, habitantes de la zona quechua.

(23) Ante la eventualidad de la captura del toro Misitu por la comunidad de K'ayau, los habitantes de la comunidad de $K$ ' oñani le ruegan a la montaña Ak'chi para que intervenga: ' $K$ ' ayau, dice, está rabiando en la quebrada, va venir, dice, para llevar tu Misitu, de tu pertenencia, de tu puna. No vas a querer, tayta." (Arguedas, 1983[1941]: 139) 
Para la gente de la puna, el Misitu es un illa. La manera de abordarlo es entonces diferente. La búsqueda del enqa, del cual el illa es una de sus hierofanías, empieza, según Flores Ochoa (1974-1976: 251), con el encuentro de una alpaca que desaparecerá en el agua dejando en su lugar una piedra amuleto:

"Es entre las brumas y la neblina que se ve una alpaca, tal como es en su verdadera figura y forma. Se le va acercándose poco a poco y desaparece en la neblina o se entra en los manantiales. En su lugar queda una piedra especial, redondeada, blanca, que es enqa."

Según Kokchi, el Misitu como la alpaca (24), que es el enqa por excelencia, hubiese podido desaparecer en el agua:

" $A$ Ay Misitu, papay! Adentro te hubieras ido, al hondo, al hondo; te hubieras dormido cuánto también” (Arguedas, 1983[1941]: 177-178).

Flores Ochoa (1974-1976: 252-252) señala ciertas recomendaciones en cuanto al vestido que se debe llevar puesto durante la búsqueda del enqa:

"Es mejor buscarlo si uno es pobre, es decir que no tiene padre, que no tiene madre, con la ropa deshilachada, el sombrero sin adornos, el chaleco sin bordados [...], con ch'ullo corriente, los pantalones rotos y sobre todo sin ganado."

El layk'a de Chipau, por la sencillez de sus vestidos, se ciñe a esas recomendaciones. Además, lleva un lazo pequeño ultilizado para jalar llamas, que son generalmente tranquilas. Entonces, va más en pos de un camélido que de un toro salvaje.

Todos estos cotejos podrían explicar la actitud confiada del layk'a de Chipau que está seguro de "capturar" al Misitu sin ayuda alguna, como lo haría si se tratase de un illa que desaparecerá al acercársele. Nos podemos preguntar si él no esperaba, como su colega (25) Kokchi, que el Misitu desapareciera en el río Negromayo.

Si el Misitu es considerado como una divinidad por la gente de la puna es porque Arguedas le ha dado ciertos caracteres de un illa. La gente de las comunidades de la puna (K'oñani et Chipau) y sus layk'as respectivos, quienes adhieren al modelo mítico de la alpaca y de los enqas, son los que asimilan el Misitu a un illa. Es por ello que no esperan combatir con un toro verdadero sino con un ser fantástico que desaparece cuando uno se le acerca. En cuanto a la gente de la comunidad de la zona quechua, ellos parten a cazar un animal salvaje cuyo simbolismo es diferente. Hemos visto que la comunidad de Pichk'achuri, aunque establecida en la ciudad Puquio, está muy ligada a la puna. Entonces, dicha comunidad comparte con la gente de esta zona la creencia en un toro illa. El alcalde de Kayao comenta este hecho:

(24) Flores Ochoa (1974-1976: 251): "No se sabe bien el origen de la alpaca, pero dicen que en el may timpu [en los orígenes de la humanidad], salieron de los manantiales y de los sitios donde hay agua, cerca de los nevados y que en el futuro, cuando lleguen las señales y el tiempo, también se volverán a ir por los mismos manantiales."

(25) Kokchi es también un layk'a: "Mandaron al vaquero Kokchi para que le avisara al Misitu, porque decían que el Kokchi era layk'a y se hacía entender con los animales." (Arguedas, 1983 [1941]: 137) 
“- ¡Encanto, encanto diciendo pichk' achuris, taytay! Nu’hay encanto, don Jolián.” (Arguedas, 1983[1941]: 90)

Podemos, por lo tanto, hacer el cuadro siguiente para demostrar el paralelismo y la oposición, desde el punto de vista religioso, entre las zonas quechua y puna en la novela Yawar fiesta.

Mitos y ritos de las zonas quechua y puna

\begin{tabular}{|l|l|l|}
\hline & Zona quechua & Zona puna \\
\hline Rito & Chaco (herranza) & Búsqueda del enqa \\
Participación & La comunidad & Uno solo \\
Vestido & Completo & Pobre \\
Instrumento de captura & Lazo & Inútil \\
Origen del Misitu & Terrestre & Acuático \\
Naturaleza del Misitu & Salqa & Illa \\
\hline
\end{tabular}

El yanantin, uno de los principios de la organización dualista andina del universo, nos ha permitido ahondar en el estudio del espacio en la novela Yawar fiesta. A la oposición ya demostrada en estudios anteriores, alto/bajo y derecha/izquierda en el pueblo de Puquio, se añade otra oposición más generalizada: zona quechua/zona puna. La puna, lugar hierofánico por excelencia, es también "uno de los operadores por los cuales se instaura la acción" (Mitterand, 1980: 201) ya que se precisa de la puna para la realización de los ritos aludidos, Chaco, Herranza y búsqueda del enqa; por eso Arguedas la construye desde el principio de la novela.

\section{MASINTIN}

Otro principio organizativo, menos evidente que el precedente pero igualmente importante en la obra de Arguedas, ha sido evidenciado por Mayer y luego por Núñez del Prado (1979: 5) que escribe:

"Masintin es el principio de identidad, solidaridad y equivalencia, que establece el hombre andino entre los componentes de dos o más parejas de opuestos complementarios en base a cualidades o circunstancias comunes a ellos. Los componentes que son Masi no se jerarquizan en orden al principio en sí, sino a criterio de edad (antigüedad en el tiempo) son equivalentes y supletorios, y se encuentran unidos entre sí por una cadena de intercambios de la misma naturaleza y/o simétricos."

Este principio, como el precedente, une los dos elementos de una misma pareja, pero, para volver a tomar la imagen de Platt, esta vez dichos elementos se sitúan en el mismo lado del espejo. Contrariamente al principio yanantin, no hay jerarquía inmutable 
inherente a la naturaleza de la pareja. Ambos principios, yanantin y masintin, se aplican a la organización familiar:

"Al interior de la familia elemental la combinación de los principios Yanantin y Masintin genera una estructura jerárquica determinada y ocho díadas de rol. Cuatro yanantin: qosay-warmi, tayta-ususi, mama-qhariwawa, pana-tura. Cuatro Masintin: Tayta-churi, mama-warmiwawa, wawqe-wawqe

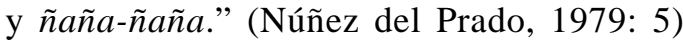

Tomemos una pareja con cuatro hijos: dos mujeres que llamaremos M1 y M2 y dos hombres $\mathrm{H} 1$ y H2. Las hijas mujeres entre ellas se tratan de $\tilde{n} a \tilde{n} a$ (por ejemplo M1 se dirige a M2 diciéndole ñaña). Por ser estas dos personas del mismo sexo, se trata de una relación masintin. Los hombres entre ellos se tratan de wawqe. Por ser del mismo sexo, ellos están también en una relación masintin. En cambio, H1 le dirá a M1 o a M2 pana por no ser del mismo sexo: están, entonces, en una relación yanantin. Asimismo, M1 le dirá a H1 o a H2 tura. Así, la relación yanantin se refleja en el vocabulario cuando los que se hablan son de sexo diferente. Por eso, una hermana no puede llamar a su hermano wawqe, ya que wawqe indica una relación masintin que solamente pueden tener dos individuos del mismo sexo. Existen, entonces, dos tipos de relaciones fraternales: uno ligado al principio yanantin y otro al principio masintin. Esta superposición de los dos principios en las relaciones familiares parece que se hacía extensiva a la ciudad del Cusco y podría explicar, en parte, la paradoja que hemos recogido en la descripción de la organización que de ella hace Garcilaso (1973: 49):

"Esta división de ciudad no fue para que los de la una mitad se aventajasen de la otra mitad en esenciones y preminencias, sino que todos fuesen iguales como hermanos, hijos de un padre y de una madre."

En este pasaje, los hermanos tienen relaciones de igualdad, de relación masintin, mientras que dos líneas más abajo parece que se trata de la relación yanantin:

"Y mandó que entre ellos hubiese sola una diferencia y reconocimiento de superioridad: que los del Cozco alto fuesen respetados y tenidos como primogénitos, hermanos mayores."

El etnólogo Arguedas (1956: 184-185) vuelve a tomar en Puquio esta noción de pueblo-familia en la que los habitantes son hermanos:

"Los ayllus de Chaupi y Qollana se consideran 'hermanos', así como Qayao y Pichqachuri, entre sí."

¿A cuál de los dos principios (yanantin o masintin) obedecen tales relaciones de fraternidad y cómo Arguedas las ha utilizado en Yawar fiesta?

Ciertos comportamientos prehispánicos entre comunidades pueden darnos luces al respecto. Cristóbal de Molina, del Cusco (1916: 78), describe las batallas rituales entre "caballeros" provenientes del Alto y del Bajo Cusco:

"Llamauan al mes de diçiembre Camay Quilla, en el qual el primero dia de la luna, los que se auian armado caualleros, asi de la parçialidad de Anancuzo [sic] como de Hurincuzco, salian a la plaza con vnas hondas en las manos, llamadas huaracas, y los de Anancuzco contra los de Hurincuzco se tirauan hondaços con vna que llaman coco, que se dan en 
vnos cardones, y uenian algunas ueçes a los brazos a prouar a las fuerças, hasta que el Inga que estaua ya en la plaza se leuantaua y los ponia en paz."

Según Garcilaso, los combatientes son "como hermanos, hijos de un padre y de una madre". Asimismo, las dos comunidades que se afrontan en la novela Yawar fiesta (K'ayau et Pichk'achuri) han sido presentadas por el etnólogo Arguedas como ligadas por lazos de fraternidad.

Un ejemplo demuestra claramente la relación existente entre los combatientes durante esas luchas. En la descripción de las batallas rituales hecha por Alencastre \& Dumézil (1953: 13), encontramos la versión quechua de una de las canciones interpretadas durante dichos enfrentamientos:

"tuka.ri.n wayna.kuna
taki.ri.n-taq sipas.kuna khayna.ta

Aqu rumi, qhisqa rumi

\section{Wawqi.y Fulano}

Naupa.q.lla.y.pi-n c'iqta.ku.n-qa

Wifala..y, wifala..y!
Jouent les jeunes gens Tocan los jóvenes et chantent les jeunes filles comme ceci: $\mathrm{Y}$ cantan las jóvenes así:

La pierre de sable, la pierre de quartz $\mathrm{La}$ piedra de arena, la piedra de "cuarzo"

Fulano Un tel Hermano tal

Seulement en mon devant se brisera Sólo delante de mí se partirá

!w, $\quad$ w.! Wifala..y, wifala..y”

Hemos visto que el término wawqey (hermano) que corresponde a la relación masintin no puede ser utilizado por las mujeres, lo que significa que puede ser utilizado solamente por individuos de sexo masculino. Las jóvenes cantan, pues, en lugar de los hombres de su comunidad. Así, el término wawqiy insiste en la relación masintin —en la que los elementos de cada pareja son iguales- que une a los participantes de las dos comunidades. Al despedirse, los combatientes confirman esta relación:

"Wata-kama-ña wayqi.y [...] À l'année prochaine mon frère!" (Alencastre \& Dumézil, 1953: 18-21).

¡Hasta el año próximo, hermano! Las dos comunidades participantes están, entonces, en el mismo nivel jerárquico, se van a enfrentar y luego del enfrentamiento una de ellas llegará a ser durante un año la Primera o Ccollana. Esta predominancia de una comunidad sobre otra no es, pues, permanente.

Por lo tanto, las dos comunidades que se enfrentan en Yawar fiesta (K'ayau y Pichk'achuri) deberían ser iguales y estar en el mismo nivel jerárquico por lo menos antes de enfrentarse. Así, una de ellas llegará a ser después del enfrentamiento la Primera (Ccollana). ¿Cómo se puede explicar, entonces, que una de las comunidades de Puquio tiene el nombre de Primera [Qollana (26)] de manera permanente?

(26) Pratlong (1982: 35-36): “En Puquio, el grupo de los Qollanas, de los conquistadores incas, acaparó las mejores tierras, las mejor dotadas de agua, las mismas que, unos siglos más tarde, suscitaron la codicia de los españoles cuando se instalaron en el pueblo, precisamente en el barrio de 
Una solución posible reposaría en la superposición e imbricación de dos sistemas diferentes. El principio yanantin supone una jerarquía estable en la que los elementos de una misma pareja son por naturaleza diferentes (alto/bajo, macho/hembra). En este sistema, la comunidad de Qollana es la Primera, ya que ella ha poseído siempre las mejores tierras y ha despertado siempre la codicia de los conquistadores, como hemos visto. En el segundo sistema, masintin, entre elementos iguales ninguna jerarquía está fijada anticipadamente, de donde surge la necesidad de un enfrentamiento, de un "encuentro" anual que fijará el rango de las comunidades durante el año. Entonces, dos comunidades diferentes pueden ser "Qollanas", pero cada una en uno de los dos sistemas.

Debemos, ahora, ahondar un poco más en el significado de esas batallas rituales, sus manifestaciones recientes y su relación con la corrida andina o Turupukllay. Alencastre \& Dumézil (1953) describen, en el capítulo "La batalla de Chiaraje", una serie de juegos violentos que tienen o tenían lugar cada año en Carnaval. Entre esos juegos se encuentra uno del cual dicen: "El juego es el warak' anakuy y el momento se llama yawar mayu 'río de sangre' (36). Algunos 'juegos' que tenían o tienen lugar "en el valle alto (C'iyaraji pata)" (22) se llaman indistintamente, en el texto bilingüe, el "encuentro" (tupay) (18) o el "juego" (pukllay) (18) del C'iyaraji. Arguedas alude seguramente a las danzas y 'luchas' del Pukllay cuando habla de danzas guerreras. Él describe el Pukllay como sigue en sus artículos sobre el Carnaval:

“... el 'pukllay' [...] los días de canto y de danza sin medida y sin temor, en la plaza, frente a las iglesias, en todas las calles; libres para la alegría y el olvido, para el baile en masa." (Arguedas, 1987[1941]: 102)

Esta primera descripción del Pukllay se completa con otra, también relativa al Carnaval, en la que la violencia toma una dimensión más importante y se asocia a la obscuridad y al agua:

"Es como un insuperable deseo de luchar y de perderse, como si la noche lóbrega dominada por la luz profunda del río se hubiera apoderado de nuestra conciencia, y se canta sin descanso, cada vez con más ansia y con más angustia. Es un desenfreno de tristeza y de coraje. Toda la esencia del vivir humano agitada con ardiente violencia en todo nuestro mundo interior sensible." (Arguedas, 1987[1942]: 154)

Recordemos que las festividades del Carnaval, durante las cuales se suele realizar el Pukllay, tienen lugar durante la estación de lluvias. Es en esta estación cuando los ríos revenrenciados por su capacidad fecundante pueden también causar la mayor cantidad de daños materiales y humanos.

¿Cuál es, entonces, la función del Pukllay? ¿Cómo la ambigüedad del Pukllay — deseo de lucha, danza, alegría y tristeza — puede ser interpretada?

González Holguín (1989) define la palabra pukllay como: "Todo género de fiestas para recrearse". En el diccionario de fray Domingo de Santo Tomás (1951)

Qollana, donde todavía hoy la influencia de los mistis es más importante que en los otros barrios [...] En Puquio, el grupo Qayao, la población de los vencidos en el momento de la conquista inca, se encuentra arrojado en las tierras más pobres, las menos provistas de agua." 
encontramos: "Juego de plaçer. Pucllay". Estas traducciones pueden, a primera vista, contradecir el estudio de Alencastre \& Dumézil (1953: 32) que describe el Pukllay:

"Las batallas campales del mismo tipo que el del C'iyaraji son como una síntesis salvaje, en estado puro, de diversos juegos violentos (principalmente de Carnaval)".

Esta cita ha sido extraída de un trabajo que procura más describir esos juegos violentos que mostrar su origen. Este hecho no menoscaba, de ninguna manera, ni la calidad ni la importancia de este estudio al que hemos recurrido y seguiremos recurriendo para nuestro trabajo. En ningún momento, en el espíritu de los participantes, el Pukllay está asociado a una batalla, en el sentido de un enfrentamiento entre enemigos. En el diccionario de González Holguín (1989), la traducción de la palabra guerra es auccay y la de la batalla aucanacuy y todo el vocabulario guerrero que incluye la palabra enemigo, según dicho diccionario, se forma a partir de dicha raíz. Además, en la descripción de Alencastre \& Dumézil (1953: 19) los miembros de un campo se dirigen sin odio a los combatientes del campo adverso, llamándoles incluso hermanos:

"Yawar unu.pi ka.spapas,

Wawqi.y fulano,

Ayrampu unu.lla-n ni.n.ki

wifalay, wifalay!

Rumi cikci.pi ka.spa-pas

Wawqi.y fulano,

Kunfitis hank'a.lla-n ni.n.ki,

Wifalay, wifalay!"
"Même si tu te trouves dans un fleuve de sang, Aunque te encuentres en un río de sangre, mon frère Un Tel,

hermano Tal,

dis: "Ce n'est que de l'eau de teinture!"

Di: “¡Es solamente agua de ayrampo!”

wifalay, wifalayi

Même si tu te trouves sous une grèle des pierres,

Aunque te encuentres bajo una granizada de piedras,

Mon frère Un Tel,

Hermano Tal,

dis: "Cene sont que des grains de maïs grillés!"

Di: ¡Son solamente granos de maíz tostado!

w., w.!"

¿Para qué sirve, entonces, la violencia que hace que esos juegos parezcan verdaderas batallas? En la canción citada, los hombres deben derramar su sangre que es también agua (27) para que, gracias al principio simila similabus, los Wamanis hagan lo propio, si se considera, como uno de los informantes de Arguedas (1956: 200), que "De los Wamanis brota la vena de sangre, el agua". Al ser uno de los objetivos de esas luchas que mucha sangre sea derramada, las comunidades se ayudan mutuamente, en sangre."

(27) Arguedas (1956: 225): “cada gota de agua constituye, como ellos dicen, ‘yawar', es decir, 
cierta manera, golpeándose o hiriéndose a veces hasta matarse para realizar el rito. Otra forma de ayuda puede provenir de un toro que, durante la "corrida", puede hacer sangrar al o a los campeones de una comunidad. Arguedas escribe (1976[1957]: 176):

"Invitaron al toro a que derramara sangre, que matara despacio."

De esta manera, llegamos al Turupukllay que nos parece ser, por las razones expuestas, una variedad metamorfoseada y sincrética del Pukllay (28). Es gracias a la llegada providencial y oportuna del toro que el Pukllay adopta esta variedad que incluye una teatralidad y un sincretismo religioso complejo que no podemos desarrollar completamente; sobre todo por la dimensión mágico-mítica que toma el toro en la zona andina y de manera especial en la zona wamánica (Calero del Mar, 2001: 111-134).

Es, por lo tanto, gracias al toro Misitu que en la novela Yawar fiesta se concreta el "enfrentamiento", regido por los principios yanantin y masintin, que hemos analizado, de las comunidades opuestas: K' ayau y Pichkachuri. La evolución del Pukllay, hacia su variedad el Turupukllay, se nota también en el vocabulario de esta novela. La palabra turupukllay tiene dos significados: el de la música que se toca con los wak'rapukus durante la corrida y la corrida misma. De las ventiséis ocurrrencias catalogadas, diecisiete corresponden a esa música y nueve a la corrida. La palabra pukllay tiene también ambos significados. De las diez ocurrencias catalogadas, seis corresponden a la música y cuatro a la corrida. Arguedas (1976: 177) tiene en cuenta la denominación de la corrida cuando nos habla de su indigenización, porque la corrida de toros se vuelve como él escribe "turu pukllay":

“Tiempo después en la Universidad y, más tarde, cuando me dediqué a estudiar folklore, aunque no volví a tener la oportunidad de observar esta misma fiesta, comprobé por mis recuerdos mejor esclarecidos e ilustrados con informaciones posteriores, que el turu pukllay (corrida de toros) aquél, como muchas otras fiestas, constituye una muestra muy elocuente acerca de cómo las costumbres españolas fueron reelaboradas por el pueblo autóctono quechua, cómo fueron transformadas en el curso de esta reelaboración y se convirtieron en indígenas."

Arguedas no precisa la fecha de la aparición de la palabra "turu pukllay", pero ambas (pukllay y turupukllay) llegan a ser rivales; la palabra turupukllay se impone, y como dice Martinet (1970: 187):

"Toda modificación de la frecuencia de una unidad trae consigo una variación de su eficacia y deja entrever una modificación de su forma. Esta última solamente se producirá a largo plazo, porque las condiciones reales del funcionamiento de las lenguas tienden a frenar las evoluciones."

Gracias a las ocurrencias de las palabras pukllay y turupukllay que hemos catalogado, Arguedas evoca la evolución del Pukllay lo que no menoscaba en nada su poder, ya que en las estructuras simbólicas de lo sagrado interviene el principio de la participación:

(28) Además de la "batalla" del Chiaraje, Alencastre \& Dumézil (1953: 31-32) mencionan otras como el yacus, el takanakuy, el sunthuthu, etc. 
"La más mínima gota de sangre contiene el mismo principio activo que toda la sangre. [...] Como la parte recuerda el todo, ella evoca también los sentimientos que recuerda el todo." (Durkheim, 1968: 328)

La sangre derramada por los capeadores, representantes de cada comunidad, durante el Turupukllay equivale a la derramada por los numerosos combatientes durante las "batallas campales" o Pukllay.

A la luz del estudio de las relaciones fraternales y considerando los principios yanantin y masintin durante las "batallas" rituales Pukllay y Turupukllay hemos establecido la presencia, en Yawar fiesta, de estos principios dualistas complementarios que organizan la familia y el universo andino. Como diría Henri Mitterand (1980: 93), estamos así en cierto modo dentro de un esquema novelesco explotado a menudo:

“... el encuentro, la confrontación de dos seres o de dos grupos puestos cada uno en los dos polos de una relación social contradictoria".

Nos parece que "la relación social contradictoria" presente en Yawar fiesta no es únicamente una oposición indios contra blancos o mestizos, ni costa contra sierra sino más que todo una oposición de tipo dualista andino, es decir, yanantin: Pichk'achuri situado arriba y K'ayau abajo. A este primer principio dualista se entrelaza otro, el masintin, que permite también explicar las oposiciones y los enfrentamientos entre las dos comunidades citadas. Así, en Yawarfiesta, el dualismo estructural andino interviene en la elaboración del espacio como un operador importante de la acción.

En síntesis, los dos principios de base de la organización del universo andino, el yanantin y el masintin, están presentes en la obra novelesca de Arguedas. Pero, ¿en qué medida esta presencia ha sido deseada conscientemente? Para responder a esta pregunta es interesante estudiar la evolución de la utilización de estos principios dualistas en la obra arguediana.

El dualismo estructural andino no interviene de la misma manera en la elaboración del espacio de las novelas Yawar fiesta, Los ríos profundos y Todas las sangres. El estudio del espacio en Yawarfiesta, publicada en 1941, demuestra que la oposición alto/ bajo, uno de los elementos de la organización dualista andina, puede ser considerada como uno de los factores de identificación de los grupos que se oponen en esos juegos, el Pukllay y su versión modificada el Turupukllay que han sido considerados como "batallas rituales" y cuyos antecedentes remontan a la época prehispánica. La toma de conciencia, en el caso de Arguedas, de esta supervivencia en los juegos mencionados es ulterior a la elaboración de Yawar fiesta. En efecto, en un comentario sobre un artículo de Gilt Contreras (1955), Arguedas (1955: 282) expresa su interés por los juegos mencionados:

"Mario Gilt ofrece algunos datos interesantes sobre las guerrillas indígenas de Canas que han sido también tema de un importante estudio de Dumézil y Alencastre (29). Ha despertado una explicable inquietud entre los antropólogos el estudio de estas tradicionales luchas entre comunidades vecinas."

(29) Arguedas alude al artículo de Alencastre \& Dumézil (1953). 
Luego, en su "Plan de Trabajo para el Verano de 1967", Arguedas (s. f.) escribe respecto a una de esas luchas:

"Estamos informados de que se realizan luchas cruentas entre solteros, el SOQOLLOY o Waqtay y que los pasos o mudanzas de la lucha son acompañados por música y cantos. En el trasfondo de esta fiesta debe haber algún mito que la sustenta."

Poco antes de 1967, Arguedas presiente, entonces, la base mítica de esas luchas que él utilizó, en 1941, en Yawar fiesta.

En Los ríos profundos, los ayllus o comunidades indias sirven más para insertar en el tejido narrativo a ciertos personajes como Palacitos (30) o para fijar los recuerdos de Ernesto (31) que para evocar la estructura dualista del universo. La presencia de esos ayllus no nos permite establecer relaciones de oposición, de solidaridad o de complementariedad susceptibles de dar cuenta del dualismo estructural andino. En Todas las sangres, publicada en 1964, encontramos una evocación interesante de dichos principios dualistas en forma de una canción acompañada de danzas, el rompe:

“- No todo triste, mamá. ¡Ahora verás! ¡A ver 'rompe’, 'rompe’!

En dos filas se alinearon en el patio los hombres. Rendón cantó:

- Uray runakuna

mayuy sirená;

yawarniki kanchu

k'ochay sirena
(Hombres del barrio de abajo, sirena del río;

¿tenéis sangre?

sirena del lago.)

La fila comandada por Justo Pariona contestó:

- Hanay runakuna,

la mar sirená,

toro mikuk' hamikun,

pak'chay sirená,

- Puma aycha aychay,

mayuy sirená,

puma yawar yawar,

la mar sirená.
(Hombres del barrio de arriba, sirena del mar,

somos gente que come toro, sirena de la cascada.)

(Mi carne es carne de puma, sirena del río; mi sangre, sangre de puma, sirena del mar.)

Replicó el coro de Rendón. Entonces Justo gritó, levantando los brazos:

-i 'Rompe', 'rompe'!

-¡Rompe, rompe! -gritaron todos.

(30) "Era el único alumno del colegio que procedía de un ayllu de indios. Su humildad se debía a su origen y a su torpeza." (Arguedas, 1983[1958]: 52)

(31) "Huyendo de parientes crueles pedí misericordia a un ayllu que sembraba maíz en la más pequeña y alegre quebrada que he conocido. [...] Los jefes de familia y las señoras, mamakunas de la comunidad, me protegieron y me infundieron la impagable ternura en que vivo." (Arguedas, 1983[1958]: 42) 
Y se lanzaron unos contra todos; a golpes de cuerpo, con los brazos cruzados, trataron de empujarse, una fila a la otra." (Arguedas, 1983[1964]: 172)

No se trata de una canción auténtica. Fue compuesta por Arguedas, que "se inspiró de fuentes folklóricas" (Fell, 1982: 840). La danza que la acompaña es una especie de batalla ritual. Su interés emana de la expresión y de la puesta de realce de diferentes oposiciones dualistas (alto/bajo, río/mar, etc.) que prueban que Arguedas empieza a tomar consciencia de los principios dualistas que rigen esas batallas en 1964, cuando se publica Todas las sangres.

Arguedas, en calidad de etnólogo, manifiesta abiertamente su interés por esas luchas solamente en 1967 como ya hemos visto. Esto constituye un ejemplo del desfase entre su obra científica y su obra novelesca. Esta le autoriza a elaborar libremente hipótesis que aquélla no le permite.

Una pregunta queda por elucidar. Si Arguedas no tenía conciencia de las implicaciones de las relaciones de oposición dualista en Yawar fiesta, a pesar de estar tan presentes, entonces, él escogió “inconscientemente" los elementos espaciales que le permiten incluir la oposición alto/bajo. La noción de poética estructural, tal como la define Todorov (1968-1973: 18-19), puede ayudarnos a dilucidar, por lo menos parcialmente, esta paradoja aparente:

"Todos ellos [los estudios sicológicos o sicoanalíticos, sociológicos o etnológicos que siendo del dominio de la filosofía o de la historia de las ideas] niegan el carácter autónomo de la obra literaria y la consideran como la manifestación de leyes que le son ajenas y que conciernen la psiquis, o la sociedad, o incluso el "espíritu humano"".

Se sabe que para Arguedas (1976: 175-178) el Turupukllay forma parte de sus recuerdos de infancia por haber visitado y vivido en pueblos donde esos acontecimientos tenían o tienen aún lugar. Se sabe también que él vivió una parte de su infancia en Puquio (Merino de Zela, 1970: 128-131) donde las supervivencias del dualismo andino han sido atestadas aún después de su muerte (Pratlong, 1982: 32-39). Hemos visto que la oposición puna/quechua incluye también una dimensión divina. Por ser religiosa, esta representación del espacio es colectiva así como lo son las nociones que corresponden a los diversos elementos de la lengua y la manera cómo la sociedad se representa los objetos de la experiencia (Durkheim, 1968: 13, 620). Arguedas dominó desde su infancia la lengua quechua, aunque no haya sido primero "monolingüe quechua", como se ha demostrado (32). Esto le permitió asimilar numerosos elementos ligados a esas manifestaciones. Así, ciertas opciones que él escogió pueden ser atribuidas a la impregnación de las supervivencias del psiquismo prehispánico andino en su espíritu. Sabemos que, al dar esta interpretación, corremos el riesgo de ser considerados "utopistas arcaicos", pero nos parece que el orden cronológico que emana de los hechos

(32) Forgues (1989: 31) escribe: "Su nodriza, Luisa de Paredes, a quien hemos encontrado e interrogado sobre este tema en Andahuaylas, nos ha afirmado que desde su más tierna edad José María Arguedas se expresaba lo mismo en castellano que en quechua. Su compañero de escuela Angel Bendezú Rodríguez, hijo del maestro de Arguedas en Puquio nos confirmó que ya al ingresar en la escuela de esta localidad el escritor era perfectamente bilingüe." 
consignados en los documentos que hemos encontrado, presentado y analizado no deja, lógicamente, otra alternativa. Insistimos en que esta explicación no puede ser exhaustiva para explicar toda la obra novelesca arguediana. Podemos decir, en cambio, que para ciertas supervivencias de la organización dualista andina Arguedas ha sido en cierto modo un actor y sobre todo un lector e inspirado intérprete; si no, ¿cómo explicar esta "anticipación"?

El estudio del espacio en las novelas Yawar fiesta, Los ríos profundos y Todas las sangres y más precisamente de un aspecto particular de la "geografía mítica" andina, el dualismo estructural, nos ha permitido avanzar en el conocimiento de la trama en la obra novelesca de Arguedas.

Dos niveles de la oposición dualista alto/bajo se encuentran entrelazados en Yawar fiesta. El primer nivel de oposición entre el alto y el bajo Puquio así como sus implicaciones sociales ya habían sido demostrados. Nosotros hemos demostrado que existe también otro nivel de oposición más general a nivel geográfico y sobre todo sagrado y mítico entre las zonas quechua y puna. La construcción de la puna, hecha con muchos detalles, permite hacer del Misitu algo sagrado y lo convierte en cosa sacrificada en los ritos del Chaco, de la Herranza y del Turupukllay. Muchos desplazamientos e itinerarios de los personajes están ligados a esta oposición generadora de la trama o historia. Esto explica la presencia de la puna y su construcción desde el principio de la novela.

A los dos principios del dualismo andino, el yanantin y el masintin, corresponden dos tipos de jerarquía. La jerarquía yanantin fija por naturaleza un Primero, Ccollana, que permanecerá así durante un periodo muy largo. En Yawar fiesta, el barrio K'ollana (Primero) debe su nombre al hecho de poseer las mejores tierras. Nada puede quitarle ese carácter. La Historia muestra que los vencedores (incas y después españoles) siempre se han establecido en ese barrio que sigue siendo el más rico y la residencia de los poderosos del pueblo. Ese dualismo de tipo yanantin corresponde al descrito por Rivers:

"Ellos [Rivers y los de su escuela] se representaban las organizaciones dualistas $[\ldots]$ como otros tantos productos históricos de la unión entre dos poblaciones diferentes por la raza, por la cultura o simplemente por el poderío." (Levi-Strauss, 1974: 179)

La jerarquía masintin, al contrario, se establece cada año gracias a las luchas entre barrios iguales que presentan características naturales, económicas o sociales equivalentes. Esas luchas rituales les permiten a los participantes derramar sangre, tanto la propia como la de los de la otra comunidad. Hay, entonces, un aspecto de reciprocidad muy fuerte, lo que ha sido señalado por algunos etnólogos:

"Marcel Mauss, luego Radcliffe-Brown y Malinowski han revolucionado el pensamiento etnológico substituyendo esta interpretación histórica con otra, de naturaleza sicosociológica, fundada en la noción de reciprocidad." (Levi-Strauss, 1974: 179)

En Yawar fiesta, "la fiesta de sangre", el establecimiento de una jerarquía masintin es, a nuestro modo de ver, el resorte principal de la dinámica novelesca. Nos 
parece que el mensaje que nos ha dejado Arguedas en esta novela, por intermedio de este aspecto sagrado del espacio, es un mensaje de optimismo. Más allá del despojo de gran parte de sus tierras, más allá de la cohabitación obligada y dolorosa con buenos y malos explotadores, las comunidades llevan a cabo todavía los ritos que les unen a la tierra, a las montañas y a sus semejantes acomodándose mal o bien a las nuevas condiciones de vida.

Sin embargo, Arguedas (1956: 231) mismo constata, algo más de diez años después, que las manifestaciones religiosas se debilitan en Puquio:

"El debilitamiento de las antiguas creencias y culto (oficial y local) remueve las bases de la vida comunal, que se muestra aun [sic] firme pero duramente combatida."

\section{Referencias citadas (33)}

ÁLVAREZ AROCHA, C. E., 1989 - El "espacio viviente” en la obra narrativa de José María Arguedas. Argos, 8-9: 63-85; Caracas.

ALENCASTRE, A. \& DUMÉZIL, G., 1953 - Fêtes et usages des Indiens de Langui (province de Canas, département du Cuzco). Journal de la Société des Américanistes, XLII: 1-118; Paris.

ARGUEDAS, J. M. \& IZQUIERDO RÍOS, F., 1947 - Mitos, leyendas y cuentos peruanos, 331p.; Lima: Ediciones de la Dirección de Educación Artística y Extensión Cultural, Col. Escolar Peruana.

ARGUEDAS, J. M., 1953 - Folklore del Valle del Mantaro, provincias de Jauja y Concepción. Folklore Americano, 1: 100-293; Lima.

ARGUEDAS, J. M., 1955 - Información bibliográfica. Folklore Americano, III, 3: 279-282; Lima.

ARGUEDAS, J. M., 1956 - Puquio, una cultura en proceso de cambio. Revista del Museo Nacional, XXV: 184-232; Lima.

ARGUEDAS, J. M., 1962 - Del retablo mágico al retablo mercantil. El Comercio, Suplemento Dominical, 30. 12. 1962: 8-9; Lima.

ARGUEDAS, J. M., 1966 (trad.) - Dioses y Hombres de Huarochirí. Naración quechua recogida por Francisco de Avila [¿1598?], 278p.; Lima:Museo Nacional de Historia, Instituto de Estudios Peruanos. Traducción de José María Arguedas; estudio biliográfico: Pierre Duviols.

ARGUEDAS, J. M., 1974[1950] - La novela y el problema de la expresión literaria en el Perú. In: Yawar fiesta: 165-174; Buenos Aires: Editorial Losada S.A.

ARGUEDAS, J. M., 1976[1957]- Canciones quechuas. In: señores e indios. Acerca de la cultura quechua: 174-185; Buenos Aires: Calicanto.

ARGUEDAS, J. M., 1983[1935] - Agua. In: Obras completas: 52-82; Lima: Editorial Horizonte, t. I.

(33) Todas las citas extraídas de los documentos escritos en lengua no española han sido traducidas por nosotros. 
ARGUEDAS, J. M., 1983[1937] - Yawar (Fiesta). In: Obras completas: 121-135; Lima: Editorial Horizonte, t. I.

ARGUEDAS, J. M., 1983[1941] - Yawar Fiesta. In: Obras completas: 69-227; Lima: Editorial Horizonte, t. II.

ARGUEDAS, J. M., 1983[1958] - Todas las sangres, 479p.; Lima: Editorial Horizonte, Obras completas, tomo IV.

ARGUEDAS, J. M., 1983[1964] - Los ríos profundos. In: Obras completas: 9-213; Lima: Editorial Horizonte, tomo III.

ARGUEDAS, J. M., 1987[1941] - Carnaval de Namora. In: Indios, mestizos y señores: 99-103; Lima: Editorial Horizonte.

ARGUEDAS, J. M., 1987[1942] - Carnaval de Tambobamba. In: Indios, mestizos y señores: 151155; Lima: Editorial Horizonte.

ARGUEDAS, J. M., 1987[1948] - Acerca del intenso significado de dos voces quechuas. In: Indios, mestizos y señores: 193-196; Lima: Editorial Horizonte.

ARGUEDAS J. M., s. f. - Cátedra de Investigaciones Folklóricas. Plan de Trabajo para el Verano de 1967, Arch. Sybila de Arguedas. In: José María Arguedas et la culture nationale dans le Pérou contemporain (1939-1969) de Fell Ève-Marie (1982): 1190- 1193; Lille: At. de Reprod. de thèses.

BEYERSDORFF, M., 1984 - Léxico Agropecuario Quechua, 129p.; Cusco: Centro de Estudios Rurales Andinos "Bartolomé de las Casas".

CALERO DEL MAR, E., 2001 - Le monde préhispanique andin dans la genèse de l'oeuvre romanesque de José María Arguedas. Thèse de Doctorat d'Université, Université de Paris $X$ Nanterre, $427 \mathrm{p}$.

CHOUVENC, J. M. \& PERROUD, P. C., 1970 - Diccionario Castellano Kechwa, Kechwa Castellano. Dialecto de Ayacucho, 200p.; Lima: Seminario San Alfonso: Padres redentoristas.

COBO, B., 1956[1653] - Historia del Nuevo Mundo, 515p.; Madrid: Ediciones Atlas, Biblioteca de Autores Españoles, t. XCII.

DURKHEIM, É., 1968 - Les formes élémentaires de la vie religieuse. Le système totémique en Australie, 647p.; Paris: Presses Universitaires de France.

FLORES OCHOA, J. A., 1974-1976 - Enqa, enqaychu, illa y khuya rumi. Aspectos mágicoreligiosos entre pastores. Journal de la Société des Américanistes, 63: 245-260; Paris.

FELL È.-M., 1982 - José María Arguedas et la culture nationale dans le Pérou contemporain (1939-1969), 1331p.; Lille: At. de Reprod. des thèses.

FORGUES R., 1989 - José María Arguedas: Del pensamiento dialéctico al pensamiento trágico. Historia de una utopía, 468p.; Lima: Editorial Horizonte.

GARCILASO DE LA VEGA, El Inca, 1973 - Comentarios Reales de los Incas, t. I, 191p.; Lima: Ediciones Peisa.

GILT CONTRERAS, M. A., 1955 - Las guerrillas indígenas de Chiyaraqe y Tocto. Archivos Peruanos de Folklore, I, 1: 110-119; Cusco.

GONZÁLEZ HOLGUÍN, D., 1989[1608] - Vocabulario de la Lengua General de todo el Perú llamada Lengua Qquichua o del Inca, 707p.; Lima: Universidad Nacional Mayor de San Marcos, Editorial de la Universidad.

GUARDIA MAYORGA, C. A., 1973 - Gramática Kechwa, 388p.; Lima: Ediciones Los Andes.

HAMON, P., 1972 - Qu'est-ce qu'une description? Poétique, 12: 465-485; Paris.

LÉVI-STRAUSS, C., 1974 - Anthropologie structurale, 454p.; Paris: Plon.

MARTINET, A., 1970 - Éléments de linguistique générale, 221p.; Paris: Armand Colin.

MAYER, E., 1977 - Andean Kinship and Marriage. American Anthropological Association, 7: 60-80; Washington D.C. 
MERINO DE ZELA, M. E., 1970 - Vida y Obra de José María Arguedas. Revista Peruana de Cultura, 13-14: 127-178; Lima.

MITTERAND, H., 1980 - Le discours du roman, 266p.; Paris: Presses Universitaires de France.

MOLINA, C. de, del Cusco, 1916[1575] - Relación de las fábulas y ritos de los Incas. In: Colección de libros y documentos referentes a la Historia del Perú, t. I: 111-190; Lima: Imprenta y Librería Sanmartín y Cía.

MOLINIÉ FIORAVANTI, A., 1985 - Tiempo del espacio y espacio del tiempo en los Andes. Journal de la Société des Américanistes, LXXI: 97-114; Paris.

NÚÑEZ DEL PRADO B., D., 1979 - Yanantin: la dualidad andina, 20p.; Cusco: Simposium Ideología y Sociedad en los Andes, IV Congreso del Hombre y la Cultura Andina.

PLATT, T., 1976 - Espejos y maíz: temas de la estructura simbólica andina, 56p.; La Paz: Centro de Investigación y Promoción del Campesinado, Cuadernos de Investigación 10.

PLATT T., 1978 - Symétries en miroir. Le concept de yanantin chez les Macha de Bolivie. Annales, E.S.C., sept.-déc., $\mathbf{N}^{\circ}$ 5-6: 1081-1107; Paris: Armand Colin. $\mathrm{N}^{\circ}$ special Anthropologie Historique des Sociétés Andines.

PRATLONG, G., 1982 - Un village des Andes péruviennes. Étude comparative. Puquio dans Yawar fiesta de J.M. Arguedas - Puquio aujourd'hui (vers 1920-1930 et en 1978-1981). Thèse de troisième cycle, Université de Paris X-Nanterre, 437p.

ROUILLÓN ARRÓSPIDE, J. L., 1967 - El espacio mítico de José María Arguedas. Comunidad, vol. II, No 6: 165-179; México.

ROWE, W., 1979 - Mito e idelogía en la Obra de Arguedas, 220p.; Lima: Cuadernos del Instituto Nacional de Cultura.

SANTO TOMÁS Fray D. de, 1951[1560] - Lexicón, o vocabulario de la lengua general del Perú, 374p.; Lima: Universidad Nacional Mayor de San Marcos.

SOTO RUIZ, C., 1976 - Diccionario quechua: Ayacucho-Chanca, 183p.; Lima: Ministerio de Educación.

TODOROV, T., 1968 - Qu'est-ce que le structuralisme? 2. Poétique, 112p.; Paris: Éditions du Seuil.

WEBERBAUER, A., 1945 - El Mundo vegetal de los Andes Peruanos, 776p., Lima: Ministerio de Agricultura. 